\title{
Receptor Cell Regeneration and Connectivity in Olfaction and Taste ${ }^{1}$
}

\author{
BRUCe OAKLey AND DAvid R. RIDdLE ${ }^{2}$ \\ Department of Biology, The University of Michigan, Ann Arbor, Michigan 48109
}

The capacity of adult mammalian gustatory and olfactory receptor cells to regenerate and make synaptic reconnections provides examples that may be useful in initiating replacement of other kinds of sensory receptor cells. The sensory code for taste quality may not be degraded by taste receptor cell turnover because axons probably recouple to the appropriate type of new receptor cell by axon-receptor cell affinity. Experiments on the development and regeneration of taste receptor cells suggest that they regenerate and turn over by recapitulating the late but not the early steps in taste bud development. To evaluate the replacement of vertebrate olfactory receptors, we began by characterizing the spatial pattern of primary olfactory projections in rainbow trout. Contiguous clusters of HRP-labeled olfactory receptor neurons (ORN) make highly divergent projections to the olfactory bulb. Retrograde transport of fluorescent latex beads revealed that a given restricted site in the glomerular layer received axons from ORNs widely scattered in the epithelium. Hence, ORN axons do not form point-to-point or regional topographic maps. Rather, the olfactory epithelial sheet makes a plane-to-point or holographic-like projection, since any given point in the glomerular layer receives information from the entire olfactory epithelial plane. Receptor cells that reacted with the lectin pokeweed agglutinin were highly dispersed in the olfactory epithelium with axons widely scattered in the olfactory nerve. Yet, as a consequence of the extensive reaggregation of axons at the nerve-bulb interface, the lectin-positive axons fasciculated and converged into a subregion of the glomerular layer. This is consistent with the view that there are many dispersed sets of ORNS whose axons fasciculate and converge to subregions of the olfuctory bulb. 1 gyz Academic Press, Inc.

\section{INTRODUCTION}

Chemosensory receptor cells behave like other kinds of epithelial cells and turn over with average lifespans in

\footnotetext{
${ }^{1}$ Supported in part by NIH Grant DC00083 and a University of Michigan Rackham Predoctoral Fellowship.

${ }^{2}$ Now at the Department of Neurobiology, Duke University Medical Center.
}

mammals of ca. 30 days for olfaction $(9,15)$ and 10 days for taste $(2,8)$. While chemoreceptor cell turnover refurbishes the sensory sheet, such replacement of receptor cells necessarily alters synaptic connections. How are stable sensory codes for taste or odor quality maintained during the periodic disruption of synaptic contacts engendered by the replacement of moribund chemoreceptor cells?

\section{THE TURNOVER AND REGENERATION OF TASTE RECEPTOR CELLS}

Taste axons break connections with old, dying receptor cells and establish new synaptic connections with young receptor cells. The pronounced variance in the absolute level of responsiveness among single taste fibers may reflect the waxing and waning of synaptic contacts during receptor cell movement and turnover. More important than such quantitative fluctuations, the turnover of taste receptor cells threatens the stability of the sensory code for taste quality. It is unlikely that axons stabilize their messages for taste quality by controlling the chemical response of the taste receptor cells they innervate. Although taste axons induce taste buds during a sensitive period in development $(11,12)$, maintain adult taste buds trophically (19), and regulate keratin expression (22), there is evidence that taste axons do not dictate the chemical specificity of the receptors cells they innervate $(16,17)$. Yet, branches of a single taste fiber have closely similar relative responsiveness to taste solutions (18). This evidence suggests that branches of a taste axon may utilize cellular affinities to synapse with appropriate receptor cells, and thereby maintain the sensory code for taste quality (20).

Because replacement of chemoreceptor cells is the rule, studies of taste (21) are useful in addressing other general issues in sensory receptor cell regeneration, such as the extent to which regeneration recapitulates development. Unlike regeneration in adults, denervation in development can irreversibly damage the gustatory competence of the lingual epithelium (Oakley, unpublished observations). Taste bud development is a more prolonged and elaborate process than the regeneration of taste buds from stem cells in adults $(4,23)$. Thus, it is not surprising that the IXth nerve can main- 
tain many more taste buds in the adult than it can induce during development $(11,12)$.

In addition to these studies that focused on how restricting the nerve supply affects the development and maturation of taste buds, we found that increasing the nerve supply to taste buds can accentuate inhibition. Taste responses were reduced by about $50 \%$ with an 11.5-min half-life of the inhibition (24). As reinnervation in other sensory systems becomes clinically feasible, it may be important to evaluate whether profuse reinnervation generates excessive or dysfunctional inhibition.

\section{AXONAL SUBSETS WITHIN PLANE-TO-POINT HOLOGRAPHIC-LIKE PROJECTIONS TO THE OLFACTORY BULB}

The short dendrite of an olfactory receptor neuron (ORN) samples odorants in the epithelial mucus, while its axon is extended to make synaptic connections in the glomerular layer of the olfactory bulb. The problem of the constancy of the code for taste quality during receptor cell turnover has its parallel in olfaction. As an ORN is replaced, the axon of the new neuron navigates to the olfactory bulb. Is the dead ORN replaced by one responsive to the same odorants? Does the new axon replicate the old connection to the olfactory bulb to prevent degradation of the olfactory code for odor quality by turnover of receptor neurons? Prior to undertaking experiments to evaluate mechanisms that might stabilize the code for odor quality during receptor cell turnover, it was initially necessary to examine the normal spatial pattern of projections from the olfactory epithelium to the olfactory bulb.

We chose to evaluate the primary olfactory projections of rainbow trout (Oncorhynchus mykiss) because salmonid olfactory systems are notable for stable odor memories that mediate homing behavior $(5,10)$ and because their olfactory epithelium or rosette can be isolated without damage to the olfactory bulb $1 \mathrm{~cm}$ away. Three weeks after epithelial labeling, HRP-filled axons were observed coursing tangentially along the olfactory nerve layer of the olfactory bulb before penetrating radially to terminate in the glomerular layer. Even when less than $15 \%$ of the olfactory epithelium was stained by HRP crystals, the labeled axons projected to widespread regions of the olfactory bulb ( $n=11$ trout). Hence, projections to the olfactory bulb were not pointto-point, or even regionally topographic; axons from an ORN cluster diverged markedly with no apparent spatial correspondence between the epithelial locus of the cluster and the widespread distribution of its labeled terminals in the glomerular plane.

With fully divergent ORN projections, it follows logically that any given point in the glomerular layer should receive axons that converge from the entire rosette.
Rhodamine-conjugated latex beads injected into the glomerular layer were retrogradely transported to ORN dendrites and somas in the epithelium ( $n=9$ trout). For injections encompassing only $1-10 \%$ of the glomerular layer, the rhodamine-labeled receptor cells were scattered from the tip to the base of every lamella. The distribution of labeled receptor somas was unrelated to the position of the dye injection in the glomerular layer. These observations were substantiated by double-label experiments in which we injected rhodamine-tagged beads and fluorescein-tagged beads either near together or far apart in the glomerular layer of the same olfactory bulb. Even with well-separated rhodamine and fluorescein injection sites, the red-labeled and the green-labeled receptor cells were widely dispersed and intermixed in the olfactory rosette. Adjacent red and green receptor cells were routinely observed, but double-labeled cells were present only when the bulbar injection sites overlapped. Therefore, axons generally must not bifurcate over significant distances in the glomerular layer. From the quantitative plots of the epithelial positions of red and green ORNs, it was impossible to predict whether the bulbar injection sites had been near together or far apart. Remarkably, as a percentage of their own fluorescent class, red cells and green cells were equally numerous on each of the lamellae, even when the rhodamine and fluorescein injection sites were far apart in the glomerular layer (Figs. $1 \mathrm{~A}$ and 1B). This is explicable if axons from a given lamella form rather even, divergent projections throughout the glomerular layer.

From anterograde and retrograde mapping, we concluded that any given point in the olfactory bulb receives axons from receptor cells that are widely dispersed in the olfactory epithelium. That is, from the perspective of a point in the glomerular layer, the primary olfactory projections are plane-to-point, where the plane is the epithelial sheet. Hence, the morphological connectivity between the olfactory epithelium and the glomerular layer exhibits a feature of holographic maps, since any given point on the glomerular layer receives information from the entire olfactory epithelial plane (25).

Before evaluating whether ORN axons scatter randomly, we had to characterize the morphology of the glomerular layer. We found that most, probably all, ORNs reacted with antiserum to keyhole limpet hemocyanin (anti-KLH, U.S. Biochemical), at dilutions of 1:1000-10,000. Staining was completely eliminated by preabsorption with $\mathrm{KLH}(10 \mu \mathrm{g} / \mathrm{ml})$. Since only the primary olfactory neurons were reactive to anti-KLH, it conveniently served to stain and subdivide the glomerular layer into nine fields based upon morphological difference in axon terminations and gaps between clusters of terminals. To generate a two-dimensional representation of the nine fields, the glomerular layer was pro- 

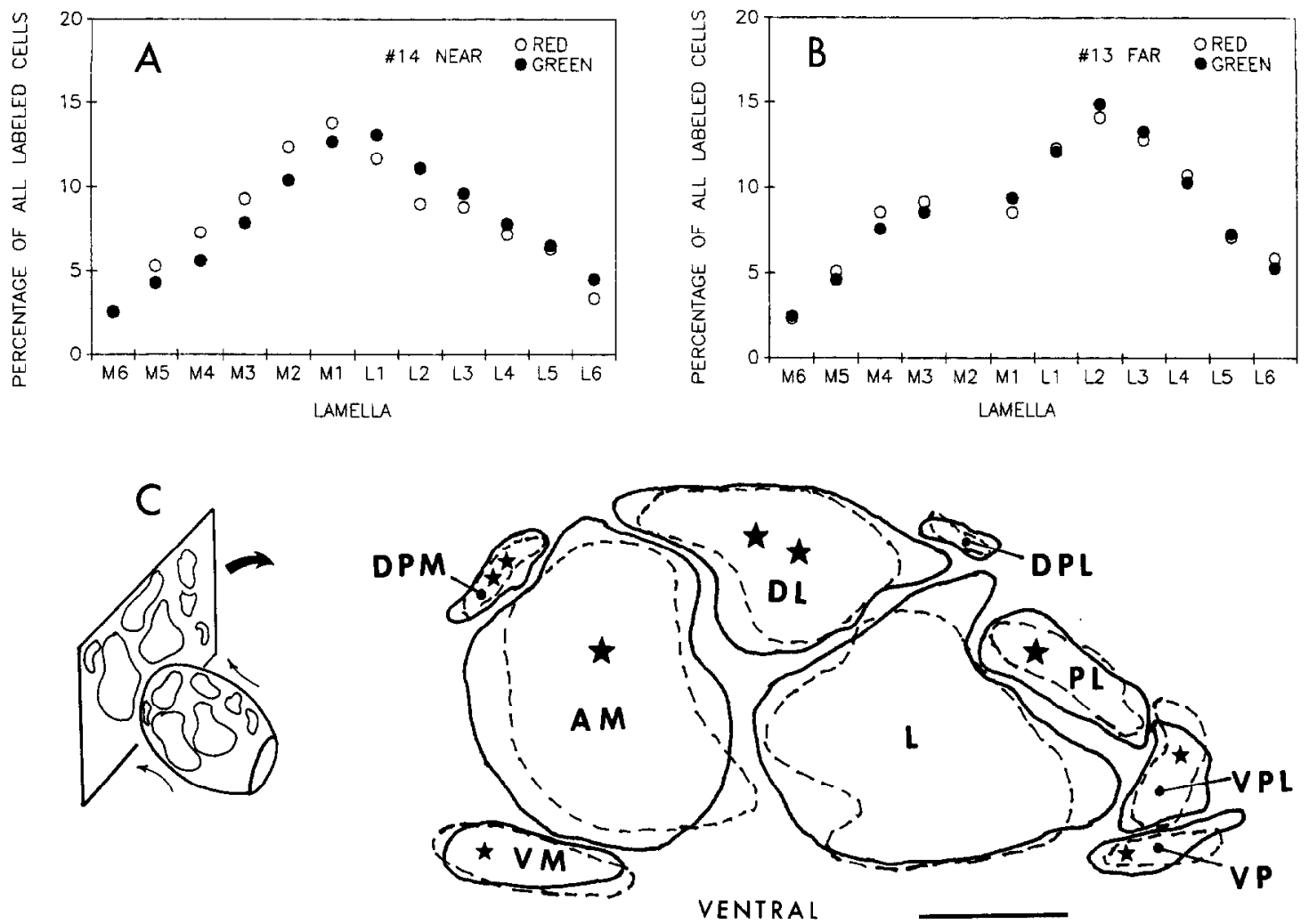

FIG. 1. Serial, $20-\mu \mathrm{m}$ sections of the olfactory epithelium were examined for fluorescent receptor cells 10 days after an olfactory bulb received an injection of rhodamine-labeled beads and an injection of fluorescein-labeled beads in the glomerular layer. The percentage distribution of the fluorescent receptor cells among a rosette's lamellae is shown for rhodamine beads (open circles) and fluorescein beads (filled circles) injected near together in the glomerular layer of one fish (A) and in far apart in another (B). Since the anterior lamellae (e.g., lamellae medial 5,6 and lateral 5,6 ) were small, they supplied fewer axons to the bulb, and accordingly contribute to the convex shape of the curves. The conjunction and near conjunction of open and closed circles for each lamella indicates that the percentage of all fluorescein-labeled cells located in a given lamella was closely similar to the percentage of all rhodamine-labeled cells present in the same lamella. This marked similarity of the percentage distributions of red and green cells across lamellae held even when the fluorescein and rhodamine injection sites were far apart in the glomerular layer (compare A and B). (C) Camera lucida tracings were made of each normal glomerular field in every fourth horizontal section. Digitized measurements of the maximum linear breadth of each field present in the aligned tracings allowed representation of the size and position of the glomerular fields onto a coronal plane at the rostral pole of the olfactory bulb as shown at the left in $\mathrm{C}$. In the coronal folded-out projection of the nine glomerular fields for a representative trout, the solid lines represent the glomerular field borders in the normal olfactory bulb and dashed lines the field borders in the contralateral reinnervated bulb (14 weeks after olfactory nerve transection). In both the normal and reinnervated bulb the relative density of staining of pokeweed agglutinin reactive axons is indicated as intense (two stars), moderate (one star), and absent (no stars). The location of the glomerular fields are designated by abbreviations: A, anterior; D, dorsal; L, lateral; $M$, medial; $P$, posterior; and V, ventral. Scale line $=1 \mathrm{~mm}$.

jected and folded out onto an imaginary coronal plane at the rostral tip of the olfactory bulb (Fig. 1C).

We examined ORN regeneration $2-14$ weeks after unilateral transection of the olfactory nerve in nine trout. Initial extensive receptor cell degeneration was followed by substantial reinnervation of the olfactory bulb within 10-14 weeks after nerve transection. The pattern of the nine glomerular fields was rather well reconstituted (dashed lines in Fig. 1C), although the experimental olfactory bulb was reduced in size compared with the contralateral bulb.

By staining the complete primary olfactory projection, anti-KLH allowed us to search for markers of subsets of olfactory axons that projected to subregions of the glomerular layer. The lectin pokeweed agglutinin (PWA; $n$-acetylglucosamine specificity) reacted with the dendrite and axon of many receptor cells, and occasionally with an entire receptor cell. The PWA-positive receptor cells were extensively scattered in the epithelium, with axons widely dispersed in the olfactory nerve. Yet, upon reaching the olfactory bulb, the scattered PWA-positive axons fasciculated extensively, aggregated, and projected to about two-thirds of the glomerular layer, leaving one-third (two of nine glomerular fields) without PWA-positive fibers (Fig. 1C). The PWA-negative areas were abundantly innervated by other axons (compare the bracketed regions in Figs. 2A and 2B). As revealed by anti-KLH and PWA, primary 

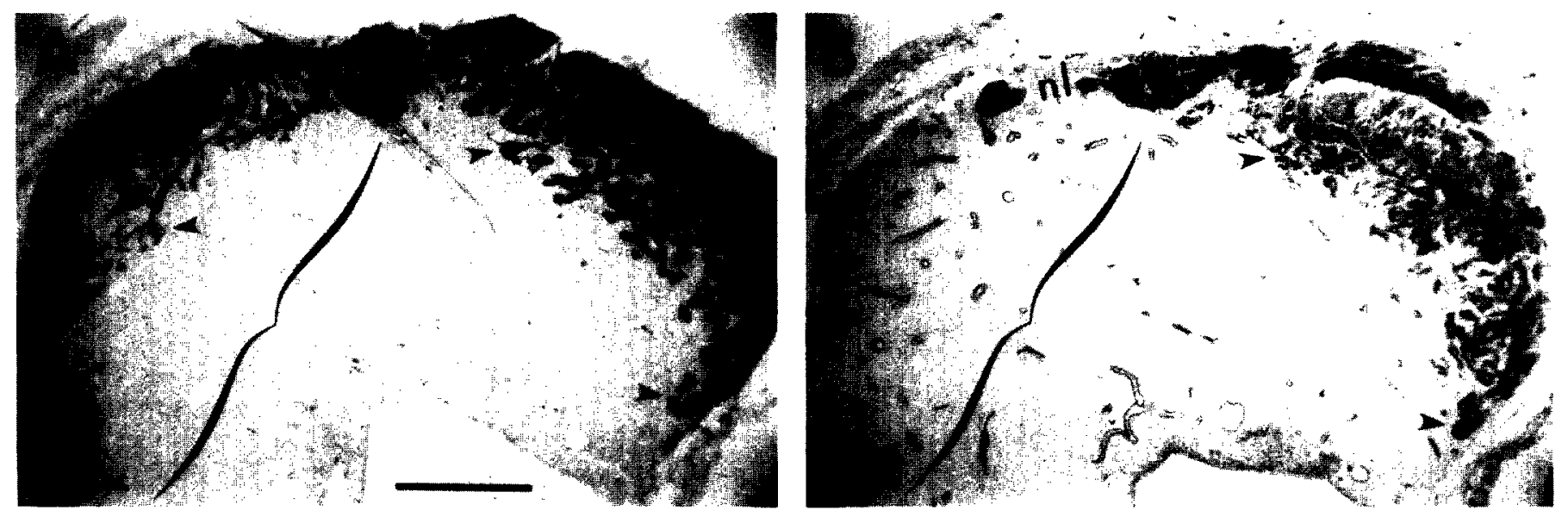

FIG. 2. The bracket shows that the lateral field of the glomerular layer was abundantly supplied with olfactory axons, as revealed by immunocytochemical staining with antiserum against KLH (A). However, the lateral field axons were not PWA positive (bracket in B), in contrast to axons in the medial region, as seen in a neighboring horizontal section. Arrowheads indicate some of the many clusters of axon terminals. nl, nerve layer superficial to the glomerular layer. Scale line $=0.3 \mathrm{~mm}$. See text.

olfactory axons do not project at random to the olfactory bulb. Rather, at the nerve-bulb interface, many axons with shared glycoconjugates systematically reassort, aggregate, and terminate together.

In summary, anterograde HRP labeling and retrograde fluorescent bead labeling revealed plane-to-point projections that have holographic characteristics. The primary olfactory projections of rainbow trout are neither point-to-point nor regionally topographic. Nor are they random; they are orderly. At the nerve-olfactory bulb interface, dispersed axons with $n$-acetylglucosamine glycoconjugates coalesce into fascicles and terminate together in several morphological fields of the glomerular layer. The primary olfactory projections examined in amphibia and mammals have been reported to be diffuse within regions, not point-to-point $(1,6,7,14)$ reviewed in (13). A given site in the rat olfactory bulb may receive input from ORNs scattered over more than half of the olfactory epithelium (1). Rather than being arranged by rules of somatotopy, primary olfactory projections may be organized in accord with the shared expression of odorant receptor molecules (3).

\section{REFERENCES}

1. Astic, L., D. SAUCIER, AND A. Holley. 1987. Topographical relationships between olfactory receptor cells and glomerular foci in the rat olfactory bulb. Brain Res. 424: 144-152.

2. Beidler, L. M., AND R. L. SMallman. 1965. Renewal of cells within taste buds. J. Cell Biol. 27: 263-272.

3. Buck, L., AND R. AXEL. 1991. A novel multigene family may encode odorant receptors: a molecular basis for odor recognition. Cell 65: 175-187.

4. Cheal, M. L., AND B. OAKLey. 1977. Regeneration of fungiform taste buds: Temporal and spatial characteristics. J. Comp. Neurol. 172: 609-626.

5. Doving, K. B. 1986. Functional properties of the fish olfactory system. In Progress in Sensory Physiology. 6 (D. Ottoson, Ed.), pp. 39-104. Springer-Verlag, Berlin.

6. Dubois-Dauphin, M. E. Tribollet, and J. J. Dreifuss. 1981. Somatotopic relations between the olfactory mucosa and the olfactory bulb in the triton. Brain Res. 219: 269-287.

7. Duncan, H. J., W. T. Nickeld, M. T. Shipley, and R. C. GesTELAND. 1990. Organization of projections from olfactory epithelium to olfactory bulb in the frog, Rana pipiens. J. Comp. Neurol. 299: 299-311.

8. FARBMAN, A. I. 1980. Renewal of taste bud cells in rat circumvallate papillae. Cell Tissue Kinet. 13: 349-357.

9. Graziadei, P. P. C., and Monti Graziadei, G. A. 1979. Neurogensis and neuron regeneration in the olfactory system of mammals. I. Morphological aspects of differentiation and structural organization of the olfactory sensory neurons. J. Neurocytol. 8: 1-18.

10. HASLER, A. D., AND A. T. SCHOLZ. 1983. Olfactory Imprinting and Homing in Salmon. Springer-Verlag, New York.

11. Hosley, M. A., S. E. Hughes, AND B. OAKLey. 1987. Neural induction of taste buds. J. Comp. Neurol. 260: 224-232.

12. Hosley, M. A., S. E. Hughes, L. L. Morton, And B. OAKLey. 1987. A sensitive period for the neural induction of taste buds. $J$. Neurosci. 7: 2075-2080.

13. KAUER, J. S. 1991. Contributions of topography and parallel processing to odor coding in the vertebrate olfactory pathway, Trends Neurosci. 14: 79-85.

14. Mackay-Sim, A., AND M. H. Nathan. 1984. The projection from the olfactory epithelium to the olfactory bulb in the salamander, Ambystoma tigrinum. Anat. Embryol. 170: 93-97.

15. Moulton, D. G. 1975. Cell renewal in the olfactory epithelium of the mouse. In Olfaction and Taste $V$ (D. Denton, Ed.), pp. 111-114. Academic Press, New York.

16. NeJAD, M. S., AND L. M. BeIDLER. 1987. Taste responses of the cross-regenerated greater superficial petrosal and chorda tympani nerves of the rat. Ann. N. Y. Acad. Sci. 510: 523-526. 
17. OAKLEY, B. 1967. Altered temperature and taste responses from cross-regenerated sensory nerves in the rat's tongue. J. Physiol. 188: $353-371$.

18. OAKLEY, B. 1975. Receptive fields of cat taste fibers. Chem. Senses Flavor 2: 52-63.

19. OAKLEY, B. 1985. Trophic competence in mammalian gustation. In Olfactory and Gustatory Influences on the Central Nervous System. (D. Pfaff, Ed.), pp. 92-103. The Rockefeller University Press, New York.

20. OAKLEX, B. 1990. On the neurotrophic support of sensory receptor cells. In Olfaction and Taste $X$ (K. B. Doving, Ed.), pp. 186195. GCS Press, Oslo.

21. OAKLEY, B. 1991. Neural-epithelial interactions in taste bud regeneration. In Regeneration of Vertebrate Sensory Receptor Cells
(J. Whelan, Ed.), pp. 277-287. Ciba Foundation Symposium, London.

22. OAkley, B, L. H. Wu, A. Lawton, and C. Desibour. 1990. Neural control of ectopic filiform spines in adult tongue. Neuroscience $36: 831838$.

23. Oakley, B., D. E. Labelle, R. A. Riley, K. Wilson, and L. H. Wu. 1991. The rate and locus of development of rat vallate taste buds. Dev. Brain Res. 58: 215-221.

24. Riddle, D. R., S. E. Hughes, C. R. Belczynski, C. L. DesiBOUR, AND B. OAKLEY. 1990. Inhibitory interactions anong rodent taste axons. Brain Res. 533: 113-124.

25. RIDDLE, D. R., AND B, OAKLEY. Evaluation of projection patterns in the primary olfactory system of the rainbow trout. $J$. Neurosci., in press. 